\title{
Fragment Reattachment of Complicated Maxillary Central Incisor Crown Fracture in 8-year-old Female Child - A Case Report
}

\author{
Nagarajan $\mathrm{S}^{1}$, Sanjeev Singh ${ }^{2}$, Aditi Kapur ${ }^{3}$, Ashima Goyal ${ }^{4}$, Gauba Krishan $^{5}$
}

\begin{abstract}
Management of complicated crown fracture is one of the frequently faced clinically challenging situations. Crown fracture of anterior teeth is a common form of dental trauma affecting children and adolescents. One of the methods of managing such a situation is reattachment of the fractured crown segment to the parent tooth. This case report describes the treatment of complicated crown fractures in maxillary right and left central incisors of an eight-year-old girl child who reported to the Pedodontics Department. The fractured segments were reattached and apexification was done, and the patient was reviewed to evaluate the treatment plan's success.

Keywords: Aesthetic treatment, Children, Crown-root fracture, Fragment reattachment, Maxillary incisors, Traumatic dental injury.

Journal of South Asian Association of Pediatric Dentistry (2021): 10.5005/jp-journals-10077-3090
\end{abstract}

\section{INTRODUCTION}

Traumatic dental injuries (TDI) are more common in young children affecting both deciduous and permanent dentition. According to Tewari et al. ${ }^{1}$ the prevalence of TDI in children less than six years is $15 \%$ and for $>6$ years it is $12 \%{ }^{1}$ And these accounts to $18 \%$ of all injuries in children aged from 0 to 6 years of age. ${ }^{2}$ Trauma involving upper central incisors are more common than lower central incisors due to their anatomic position and an increased tendency to get hit during a traumatic event. ${ }^{3}$ Injuries affecting deciduous dentition are most commonly subluxation injuries since the pliable alveolar supporting structures dissipates the trauma delivered on the teeth. ${ }^{4}$ However, trauma involving permanent anteriors usually results in crown fractures or crown-root fractures. Crown-root fractures (CRF) involve enamel, dentin, and cementum and they account for $5 \%$ of all dental injuries in permanent teeth. ${ }^{5,6}$ Depending on pulp involvement, these fractures can be classified as uncomplicated (without pulp exposure) or complicated (with pulp exposure).

Although uncomplicated crown fractures are more frequently seen, Complicated crown fractures involving pulp poses a clinically challenging situation needing multidisciplinary approach to address the situation. IADT (International Association of Dental Trauma) guidelines, 2020 has included fragment reattachment as management plan only for uncomplicated fractures, however various case reports have reported this procedure as successful method for managing Crown-Root fractures. ${ }^{7}$ This case report presents Crown- root fracture reattachment procedure in maxillary central incisors in a girl child by using light cure flowable composite resin, after Etching and application of bonding agent.

\section{Case Description}

An eight-year-old female child came to pedodontics department with a chief complaint of Trauma in upper front tooth region ten days back. History revealed that the child had a fight with her brother and was hit by fist. Patient had no relevant past medical history, and no past dental history. Extraoral Injury revealed

\begin{abstract}
${ }^{1-5}$ Pediatric Dentistry, Oral Health Sciences Center, Postgraduate Institute of Medical Education and Research, Chandigarh, India

Corresponding Author: Sanjeev Singh, Oral Health Sciences Center, Postgraduate Institute of Medical Education and Research, Chandigarh India, Phone: +91 9780554348, e-mail: san.bajaj88@gmail.com

How to cite this article: Nagarajan S, Singh S, Kapur A, et al. Fragment Reattachment of Complicated Maxillary Central Incisor Crown Fracture in 8-year-old Female Child- A Case Report. J South Asian Assoc Pediatr Dent;2021;4(3):197-199.
\end{abstract}

Source of support: Nil

Conflict of interest: None

healing bruises in upper lip. Intraoral examination showed multiple fragment segments attached to each in relation to 11 and 21 teeth with some of the fragments missing at the mesial incisal edge of both the teeth (Fig. 1a,b,c). Patient had tenderness in the associated 11 and 21. No signs of Pus or sinus were noted. Mobility of the teeth was not assessed due to fear of complete fracture of crown. Since both the central incisors had complicated fracture, the status of overjet was unable to be assessed. Radiographic examination revealed complicated crown fracture in 11 and 21 extending till Cemento-enamel Junction with multiple fragments (Fig. 2a,b). Considering the younger age of the child CBCT was not advised to lessen the radiation exposure $(\mathrm{R})$.

Informed consent was obtained explaining the success rate and limitations of the treatment plan. Patient's and parent's perspective regarding the change in color of the injured teeth following treatment was also obtained. Patient was planned to be recalled for regular follow up and his/ her willingness to comply was taken into consideration.

\section{Treatment Plan}

Considering the age of the patient, location of tooth fracture, extent of fracture in relation to adjacent periodontium, root development status, and grade of mobility of teeth following treatment plan was proposed: 


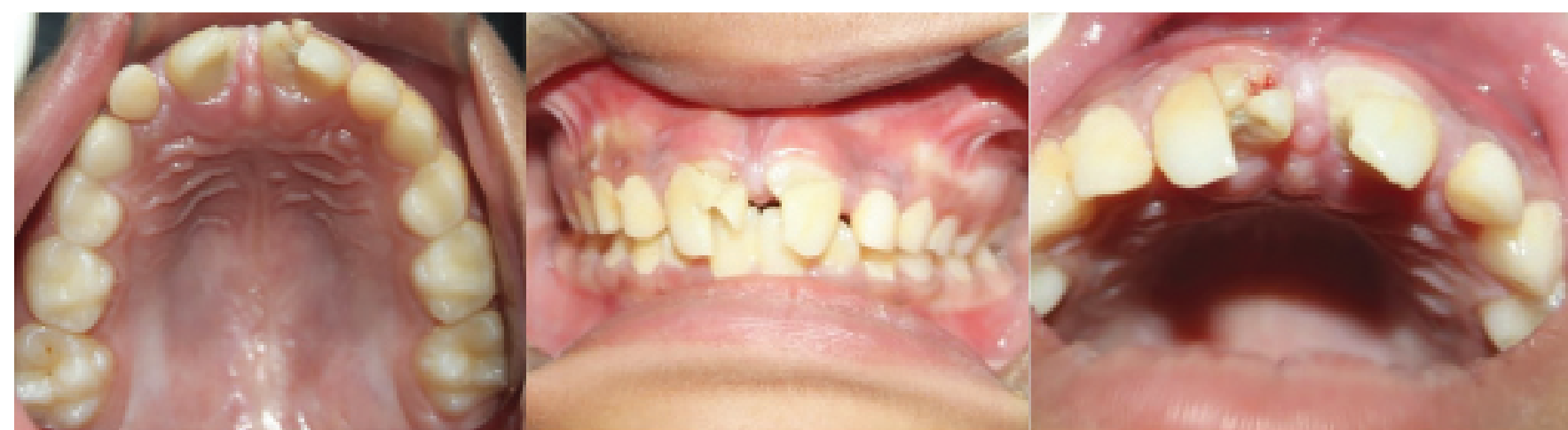

Figs. 1a to c: (a) Occlusal view, (b) Labial view, (c) Oblique view showing bleeding pulp
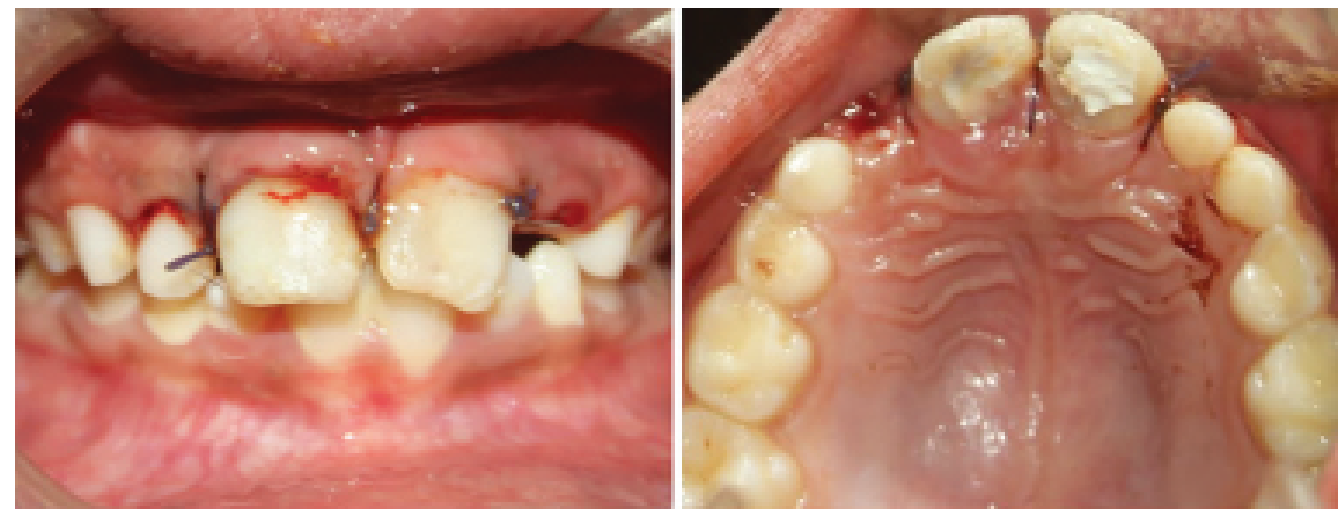

Figs. 2a and b: Intraoperative images showing reattached fragmented teeth segments in 11 and 21 (combined with flap surgery and Apexification) (a) Labial view, (b) occlusal view

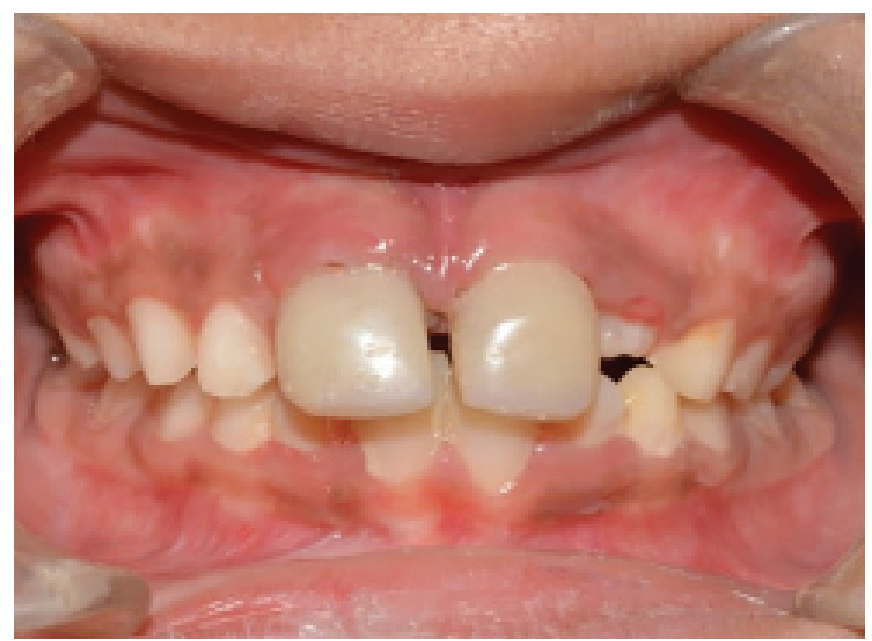

Fig. 3: Postoperative image showing Indirect composite crown placed in 11 and 21

\section{First Appointment}

- Reattachment of fractured segments which are visible coronally

- Flap elevation to expose the root fracture line in 11

- Reattachment of root fracture

- Biodentin Apexification of 11 and 21

\section{Second Appointment}

- Additional endodontic-Fiber postplacement in 11,21

\section{Third Appointment}

- Indirect composite crown restoration of 11 and 21

\section{Treatment Procedure}

Initially Child's behavior was assessed to be Frankl's rating 3 (i.e. Positive). Tell- show-do and positive reinforcement was done for behavior management of the child. Patient's extraoral area and intraoral mucosa was wiped with 5.0\% Povidone- lodone solution. Then all the fractured tooth segments were positioned back to the normal position apposing their fracture lines and luted with flowable composite (Coltene-Brilliant flow A3/D3) after Etching (using $3 \mathrm{M}$ ESPE Scotchbond ${ }^{\mathrm{TM}}$ Multi-purpose Etchant) and Bonding (Using 3M ESPE Adper ${ }^{\mathrm{TM}}$ Single bond 2 Adhesive). With this initial procedure it was made sure that the coronal fractured segments were assembled as a single unit. Then to address the fracture which is present near the CEJ, full thickness mucoperiosteal - Envelope Flap was raised with an intrasulcular incision, starting from distal aspect of 22 to 12, exposing the fracture present at the level of CEJ. This procedure was carried under Local anesthesia.

After achieving initial stability of the broken crown segment in both 11 and 21, endodontic treatment was started. Since the incisors were at Nolla stage 9 initially apexification was planned. So after pulp debridement and biomechanical preparation Surgifoam (Ethicon ${ }^{{ }_{-}}$ Surgifoam ${ }^{\text {TM }}$ U.S.P) was used as a scaffold periapically on which Biodentin apexification was done (Using Septodont Biodentine ${ }^{\mathrm{TM}}$ ). Followed by which Gutta percha lateral condensation was done. Considering the loss of initial stability in 11 and 21, additional ceramic post support was planned. For which post space preparation was done using peso reamer and Fiber Post ( $A A A^{\mathrm{TM}}$ - High intensity quartz resin post) was luted using Flowable composites (Fig. 4).

Considering the risk of secondary caries and to improve the resistance form Indirect composite crown was planned to be placed 


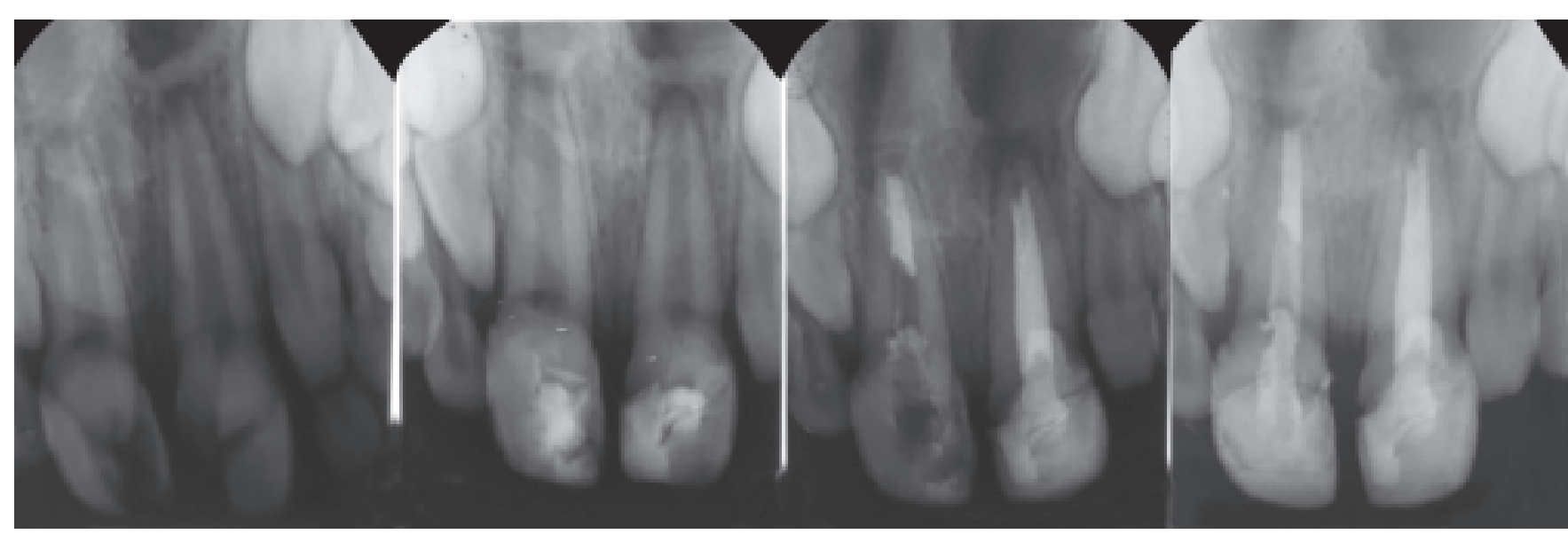

Fig. 4: IOPA images of (a) Pre-op (b) after fragment reattachment (c) Obturation in 21 following Biodentine Apexification and Post space preparation in 11 following Biodentine apexification, (d) after fiber post insertion and Indirect composite crown insertion

for both 11 and 21 (Fig. 3). So, after crown preparation retraction cords were placed to control bleeding and expose the margin of preparation. Putty impression was taken and indirect composite crown was fabricated on the cast and luted using flowable composite. Due to Pandemic, the patient was telephonically reviewed regularly, the teeth still in function without any symptoms for more than six months. The patient was also motivated to maintain oral hygiene.

\section{Discussion}

Management of Complicated crown-root fracture needs adoption of multidisciplinary approach involving surgery, endodontics, periodontics and prosthodontics. ${ }^{8}$ Tooth fragment reattachment was first reported in early 1960's and since then this procedure has undergone major changes in recent years, especially after introduction of tooth colored adhesive resin cements. ${ }^{9}$ Fragment reattachment although has its own mechanical disadvantage of getting chipped off easily, it offers better reproduction of tooth color, shape and contour, along with shorter operative time. The current case report adds to the number of other case reports being increasingly attempted by the dentists. Also the effectiveness of tooth colored fiber post in increasing the Resistance form has been evaluated. To overcome the drawback of reduced resistance form, additional Fiber post was used in this case, which has been shown to decrease the stress delivered on the reattached tooth fragment as it interlocks the two fragments ${ }^{10}$. Similarly Adanir et al. determined that the physical characteristics of the fiber post were important in the stress distribution pattern and success in fragment reattachment. ${ }^{11}$

The case history presented here not only shows the fragment reattachment, but also adjoined Biodentine-Apexification been done simultaneously, since both the centrals were in Nolla stage- 9 . Biodentine was selected as a material of choice since it has a shorter setting time of 12 minutes as compared to that of MTA which is 2 hours 45 minutes $^{12}$. In case of apexification, quicker setting time eliminates the need for two step obturation as with MTA, and reduces the risk of bacterial contamination ${ }^{13}$. It is also to be noted that usage of adequate wet storage medium before reattachment is important for better optical results following reattachment (Edden et al.). ${ }^{14}$

\section{Conclusion}

Fragment reattachment appears to be clinically acceptable method for managing complicated crown root fractures in young immature upper central incisors.

\section{Reference}

1. Tewari N, Mathur VP, Siddiqui I, et al. Prevalence of traumatic dental injuries in India: a systematic review and meta-analysis. Indian J Dent Res 2020; 31: 601-614. DOI: 10.4103/ijdr.IJDR_953 19

2. Flores MT, Andersson L., Andreasen JO. International association of dental traumatology. Guidelines for the management of traumatic dental injuries. I. Fractures and luxations of permanent teeth. Dent Traumatol 2007;23(2):66-71. DOI: 10.1111/j.1600-9657.2007.00592.x

3. Juneja P, Kulkarni S, Raje S. (2018). Prevalence of traumatic dental injuries and their relation with predisposing factors among 8-15 years old school children of Indore city, India. Med Pharm Rep 91(3), 328-335. DOI: 10.15386/cjmed-898

4. Goswami, M., Rahman, B., \& Singh, S. (2020). Outcomes of luxation injuries to primary teeth-a systematic review. J Oral Biol Craniofacial Res, 10(2), 227-232. DOI: 10.1016/j.jobcr.2019.12.001

5. Andreasen JO. Etiology and pathogenesis of traumatic dental injuries. A clinical study of 1298 cases. Scand J Dent Res 1970;78:329-42. DOI: 10.1111/j.1600-0722.1970.tb02080.x

6. Turgut MD, Gönül NY, Altay N. Multiple complicated crown-root fracture of a permanent incisor. Dent Traumatol 2004;20:288-92. DOI: 10.1111/j.1600-9657.2004.00248.x

7. Bourguignon C, Cohenca N, Lauridsen E, et al. International association of dental traumatology guidelines for the management of traumatic dental injuries: 1. Fractures and luxations. Dent Traumatol 2020;36:314-330. https://doi.org/10.1111/edt.12578

8. Pavan Bajaj N. Multidisciplinary approach to the management of complicated crown-root fracture: a case report. J Int Oral Health: JIOH 2015; 7(4)88. Retrieved from https://www.ncbi.nlm.nih. gov/pmc/articles/PMC4409806/

9. Chosack A, Eidelman E. Rehabilation of a fractured incisor using the patient's natural crown-case report. J Dent Child 1964;71:19-21.

10. Oliveira GM, Oliveira GB, Ritter AV. Crown fragment reattachment: report of an extensive case with intra-canal anchorage. Dent Traumatol 2010;26(2):174-81. DOI: 10.1111/j.1600-9657.2009.00844.x

11. Adanir N, Belli S. Stress analysis of a maxillary central incisor restored with different posts. Eur J Dent 2007;1(2):67-71. PMID 19212479

12. Parirokh $M$, Torabinejad $M$. Mineral trioxide aggregate: a comprehensive literature review - Part I: chemical, physical, and antibacterial properties. J Endod 2010;36:16-27. DOI: 10.1016/j. joen.2009.09.006

13. Bachoo IK, Seymour D, Brunton P. Clinical case reports using a novel calcium-based cement. Br Dent J 2013;214:61-64. DOI: 10.1038/ sj.bdj.2013.53

14. Eden E, Yanar S, Sönmez Ş. Reattachment of subgingivally fractured central incisor with an open apex. Dent Traumatol 2007;23(3): 184-189. DOI: 10.1111/j.1600-9657.2005.00408.x 